\title{
Atendimento Escolar no Hospital Universitário da Universidade Federal do Maranhão: entre avanços e limites na formação inicial do pedagogo
}

\author{
Maria Socorro Lucena Lima ${ }^{1}$ \\ Francy Sousa Rabelo ${ }^{2}$ \\ Marilize de Morais Silva ${ }^{3}$
}

\begin{abstract}
RESUMO
Esta pesquisa visa compreender os avanços e os limites do atendimento escolar no Hospital Universitário da Universidade Federal do Maranhão através do Projeto Estudar, uma ação saudável. O aporte teóricometodológico utilizou-se do levantamento bibliográfico, baseando-se em autores como, Fonseca (1999; 2008), Taam (2004), entre outros e da pesquisa de campo, cujo lócus foi o Projeto de Extensão supracitado e as técnicas de coleta de dados foram a observação participante e a entrevista semi-estruturada com alunas do Curso de Pedagogia, participantes desta experiência como bolsistas e voluntárias. Os resultados apontaram como um dos avanços, a participação efetiva das crianças nas atividades promovidas pelo atendimento escolar hospitalar no projeto reaproximando-as com o cotidiano escolar e quanto aos limites, tem-se a ausência de discussões sobre educação em espaços não escolares no currículo, da formação do pedagogo.
\end{abstract}

PALAVRAS-CHAVE: Atendimento Escolar Hospitalar. Pedagogo. Formação Inicial.

\footnotetext{
${ }^{1}$ Doutora em Educação. Universidade Estadual do Ceará, Fortaleza, Ceará, Brasil. Orcid: https://orcid.org/0000-00016600-1194. E-mail: socorro lucena@uol.com.br.

${ }^{2}$ Mestre em Educação. Universidade Federal do Maranhão, São Luis, Maranhão, Brasil. Orcid: https://orcid.org/00000001-9831-8874. E-mail: franrabelo@ hotmail.com.

${ }^{3}$ Pedagoga. Rede Municipal de São Luis, Maranhão, Brasil. Orcid: https://orcid.org/0000-0002-2464-7576. E-mail: marilize21@hotmail.com.
} 
School Attendance at the Hospital of the Federal University of

Maranhão: between advances and limits in the initial

formation of a pedagogue

\begin{abstract}
This research aims to understand the advancement and limits of school attendance at the University Hospital of the Federal University of Maranhão through the project Study, a healthy action. The theoreticalmethodological contribution used a bibliographical survey, based on authors such as Fonseca (1999; 2008), Taam (2004), among others and field research, whose locus was the extension project above-mentioned and the data collection techniques were the participant's observation and semistructured interviews with students of the Pedagogy Course, of this experiencie participant's such as scholarship holders and volunteers. The results pointed out as one of the advancements, the effective participation of children in the activities promoted by school attendance in a hospital setting of this project, reconnecting them with daily school life, whereas regarding the limits, there is an absence of discussions about education in a non-educational setting in the initial curricular formation of a pedagogue.
\end{abstract}

KEYWORDS: Hospital School Attendance. Educator. Initial Training.

\title{
Atención Escolar en Hospital Universitario de la Universidade Federal do Maranhão: avances y límites en la formación inicial del pedagogo
}

\section{RESUMÉN}

Esta investigación tiene por objetivo comprender los avanzos y los límites de la atención escolar en el Hospital Universitario de la Universidade Federal do Maranhão a través del proyecto Estudiar, una acción saludable. La contribución teórica-metodológica se utilizó de la revisión bibliográfica, se basando en actores como Fonseca (1999; 2008), Taam (2004), y otros, además de la investigación del campo, cuyo locus fue el proyecto de extensión dicho y las técnicas de recolección de datos fueron la observación participante y la entrevista semiestructurada con alunmas del Curso de Pedagogía, participantes del proyecto como becarias y voluntarias. Los resultados apuntaron, como uno de los avanzos, la 
participación efectiva de los niños en las actividades promovidas por la atención escolar hospitalaria en la experiencia, acercándolas con la vida cotidiana escolar y, en relación a los límites, existe la ausencia de discusiones acerca de la educación en espacios no escolares en el curriculo de la formación inicial del pedagogo.

PALABRAS-CLAVE: Atención Escolar Hospitalaria. Pedagogo. Formación Inicial.$$
* * *
$$ \\ O professor é importante em todos os lugares, \\ até no hospital. \\ A. $R$., 5 anos, criança hospitalizada no \\ HUUFMA- 2017
}

\title{
Introdução
}

O processo de inclusão avança com o ideal de promoção igualitária do acesso à educação, tecnologia, entre outros. Ele se destaca por tratar de algo contemporâneo e instigante que desencadeia mudanças estruturais no âmbito social, político e cultural. A escola não se distancia desta realidade porque se responsabiliza por escolarizar pessoas, porém, quando este espaço não consegue ser alcançado por conta da diversidade vivenciada por seu alunado é preciso demonstrar soluções para que o processo de escolarização não se finde.

Dentre as buscas de soluções, tem-se o atendimento escolar em diversos espaços, dos quais, o ambiente hospitalar é um deles, daí surge uma nova proposta de trabalho. Nesta perspectiva, o profissional que atua no atendimento escolar com crianças e adolescentes hospitalizados, ou seja, aqueles que estão nas séries iniciais do Ensino Fundamental, é o pedagogo, cuja legislação que fundamenta tal prática está nas Diretrizes Curriculares Nacionais para o Curso de Pedagogia, em seu artigo $5^{\circ}$, inciso IV (BRASIL, 2006).

Esta assertiva aponta para as discussões a respeito do processo de inclusão social, ademais as políticas educacionais no tocante à formação deste 
profissional deve preocupar-se com o princípio da igualdade de direito, garantindo o acesso à educação e também à permanência destes indivíduos em se desenvolverem como sujeitos intelectual e social.

É no tocante a formação inicial do pedagogo, que este debate suscita ações de extensão universitária que visam minimizar o distanciamento da criança hospitalizada com a escola e abertura de novas frentes de trabalho a este profissional. Neste estudo, aponta-se a experiência do projeto de extensão "Estudar, uma ação saudável" desenvolvido pelo Curso de Pedagogia, na Universidade Federal do Maranhão.

Este artigo tem por objetivo compreender os avanços e limites do atendimento escolar hospitalar no Hospital Universitário da Universidade Federal do Maranhão-HUUFMA, percepção apreendida na formação inicial do pedagogo, para tanto pauta-se na abordagem qualitativa de pesquisa, por se tratar de investigar um recorte da realidade. $\mathrm{O}$ estudo se subsidiou em documentos legais como Resolução nº 41 do CONANDA(BRASIL, 1995), e em autores como Rabelo (2014), Fonseca (1999, 2008), Ceccim (1999), Taam (2004) entre outros. A coleta de dados envolveu a observação participante e buscando obter o máximo de informações sobre o objeto da pesquisa, usouse da entrevista semiestruturada (YIN, 2010), com as alunas do curso de Pedagogia, que eram bolsistas e voluntárias.

\section{Atuação docente no hospital: Formação e prática}

A inclusão educacional deve alcançar quaisquer sujeitos, inclusive àqueles que estão nos espaços não escolares, impedidos de alguma forma a adentrarem na escola regular, seja em prisões ou em hospitais. Neste sentido, a escola regular torna-se de maneira diferenciada para alcançar o direito à educação. Para Rabelo (2014) dá-se ênfase a um novo modelo de escola, aquela em que é possível o acesso e a permanência de todos os alunos, e onde "os mecanismos de seleção e discriminação, até então utilizados, são substituídos por processos de identificação e remoção de barreiras para a 
aprendizagem"(GLAT, 2007, p.16). Nesse sentido, as crianças e adolescentes hospitalizados tornam-se provocadas a romper barreiras e adentrar em outro espaço: o da escola, materializada pelas ações pedagógicas, as quais levam a esses meninos e meninas, os conhecimentos socialmente valorizados e o resgate do ser aluno tolhido pela internação.

Para ao alcance de tal ação, a formação do pedagogo não pode se distanciar deste feito, portanto, é necessário evidenciar em seu currículo, discussões que efetivam esta prática, uma vez que estão fundamentada nas Diretrizes Curriculares Nacionais para este curso, quando apontam:

Art. $4^{0}$ - O curso de Licenciatura em Pedagogia destina-se à formação de professores para exercer funções de magistério na Educação Infantil e nos anos iniciais do Ensino Fundamental, nos cursos de Ensino Médio, na modalidade Normal, de Educação Profissional na área de serviços e apoio escolar e em outras áreas nas quais sejam previstos conhecimentos pedagógicos.

Parágrafo único. As atividades docentes também compreendem participação na organização e gestão de sistemas e instituições de ensino, englobando:

II- planejamento, execução, coordenação, acompanhamento e avaliação de projetos e experiências educativas não-escolares.

Art. $5^{\circ} \mathrm{O}$ egresso do curso de Pedagogia deverá estar apto a:

IV - trabalhar, em espaços escolares e não-escolares, na promoção da aprendizagem de sujeitos em diferentes fases do desenvolvimento humano, em diversos níveis e modalidades do processo educativo (BRASIL, 2006, p. 02, grifos nossos).

Esta legislação marca os desafios da contemporaneidade na atuação do pedagogo, alcançando além dos espaços escolares, e porque não citar as crianças que estão fora da escola, muitas vezes marginalizadas e até hospitalizadas.

Observa-se então, que o curso referenciado pode oportunizar práticas pedagógicas em ambientes diversos, transcendendo as paredes da escola regular. Instituído e subsidiado legalmente o exercício da docência em espaços não escolares, inicia seu desenvolvimento a partir da ruptura com a ideologia de que o espaço do pedagogo é somente na escola (LIMA; SILVA; SANTOS, 2014). 
No tocante a atuação do pedagogo na sociedade, deve-se ter uma visão holística, ou seja, compreende-se que a educação "abrange todos os processos de formação dos indivíduos, de modo que, toda troca de saberes se constitui como uma prática educativa e pode se desenvolver nos mais variados ambientes sociais" (GOMES; SILVA; SILVA, 2011, p. 1).

Visando acompanhar esse movimento, o Curso de Pedagogia e o pedagogo devem se transmudarem, remodelarem-se, para adaptar-se ao modelo social, estruturando-se de acordo com os ambientes sociais, seja em espaços escolares ou espaços não-escolares.

O debate sobre a ação docente nestes espaços, situou-se na compreensão de educação formal, não-formal, informal, em que tais conceitos para Gohn(2006, p. 29), se constituem em:

$\mathrm{Na}$ educação formal, entre outros objetivos destacam-se os relativos ao ensino e aprendizagem de conteúdos historicamente sistematizados, normatizados por leis, [...]. A educação informal socializa os indivíduos, desenvolve hábitos, atitudes, comportamentos, modos de pensar e de se expressar no uso da linguagem, [...]. Trata-se do processo de socialização dos indivíduos. A educação não- formal capacita os indivíduos a se tornarem cidadãos do mundo, no mundo. Sua finalidade é abrir janelas de conhecimento sobre o mundo que circunda os indivíduos e suas relações sociais. [...].

Na superação deste debate, Moura e Zucchetti (2010, p.632), afirmam sobre a educação não escolar evidenciar-se em processos e procedimentos que contam com a presença do professor, metodologia definida, mecanismo de avaliação interna e externa, situações essas que por vezes até lhes visam conferir um caráter oficial, por isso a necessidade de avançar nesta discussão, para não centrar-se prioritariamente em delimitar o campo do que é formal e não formal e parecer que seu conceito baseia-se apenas no espaço que a caracteriza. Ghanem e Trilla (2008) também inferem, que a educação não escolar supera o entendimento do "lugar", e o foco é a educação permanente, em que as pessoas podem educar-se sempre. Isto não pode ser marcado pelo âmbito escolar ou não escolar, pois a ideia de educação permanente exige disponibilidade de muitos 
outros recursos educacionais, além dos escolares, e envolve situações de formação contínua, educação de adultos, educação ao longo da vida.

Logo, o atendimento escolar no espaço hospitalar referencia uma educação voltada à cidadania e revela a ligação intrínseca com a escola, cuja prática educativa envolve conteúdos escolares para as pessoas "excluídas" do sistema formal de ensino: as crianças, adolescentes, jovens e adultos hospitalizados, o que demanda a busca por inclusão social e com prática diferenciada, pois:

O fazer pedagógico no espaço não escolar está diretamente relacionado às atividades que envolvem trabalho em equipe, planejamento, formação pessoal, orientação, coordenação, sendo que o objetivo principal desse fazer está direcionado às transformações dos sujeitos envolvidos na prática pedagógica (NASCIMENTO, et al, 2010, p 63).

Assim, a formação do pedagogo para atuar em espaços não-escolares como, empresas, presídios, hospitais, museus, entre outros, exige a existência de saberes e fundamentos teóricos que possibilitem a imersão crítica e análise reflexiva sobre o perfil do ambiente e indivíduos neles presentes.

$\mathrm{Na}$ estrutura curricular do curso de Pedagogia, a formação deste profissional deve contemplar um núcleo de estudo, em que saberes e conhecimentos específicos objetivam a aprendizagem nos espaços não escolares, por se remeter as suas peculiaridades, diferentes das instituições de ensino regulares, uma vez que já está legitimado nas Diretrizes Curriculares Nacionais para o Curso de Pedagogia, apontadas neste texto.

Consequentemente, o pedagogo em formação deverá ter acesso a uma visão sobre espaços não-escolares, enfocando o papel do pedagogo nos mesmos, visando oferecer a esse profissional um olhar para as diversas possibilidades existentes no exercício de sua função.

Faz-se presente assim, um novo perfil de pedagogo para atuar nos mais variados espaços da sociedade, sendo um deles: o hospitalar, que pode oportunizar às crianças e adolescentes internados, atividades escolares, estabelecendo conexões com o mundo escolar. Daí, o atendimento escolar neste 
ambiente se apresenta como uma estratégia diferenciada, ou seja, a de alterar o dia-a-dia da internação destes sujeitos e proporcionar uma maior humanização e interação social, assim como dar continuidade ao aprendizado dos conteúdos escolares vedados com a internação, visto que durante a infância e a adolescência, tanto um quanto o outro estão construindo e reconstruindo saberes no espaço escolar, pois segundo Matos e Mugiatti (2007, p. 28):

[...] a criança e o adolescente, nessa fase, se encontram em pleno período de aprendizagem, que estão eles ávidos por novidades, essas operadas pela observação, experiência e comunicação, elementos constitutivos da aprendizagem em condições permanentes.

Indubitavelmente, a ruptura da rotina escolar produz desconfortos e pode prejudicar os estudantes na sua volta à escola e quiçá até motivar o afastamento definitivo dela. Por isso, as intervenções do pedagogo nas atividades pedagógicas realizadas no hospital podem promover o bemestar e impedir entraves no desenvolvimento intelectual das crianças enfermas, provocando ainda a possibilidade de retorno às salas de aula das classes regulares de ensino.

Há, portanto, uma necessidade legal de inserção de classes escolares em espaços hospitalares como forma de garantir o direito à educação, isto já está previsto na alteração da Lei de Diretrizes e Bases da Educação Nacional (LDBEN), pela Lei 13.786 de 24 de setembro de 2018, que diz:

Artigo $4^{\circ}$ - É assegurado atendimento educacional, durante o período de internação, ao aluno da educação básica internado para tratamento de saúde em regime hospitalar ou domiciliar por tempo prolongado, conforme dispuser o Poder Público em regulamento, na esfera de sua competência federativa (BRASIL, 2018, p.1).

Este dispositivo já havia sido determinado desde o ano de 1995, pela Resolução $\mathrm{n}^{\circ} 41$ do Conselho Nacional dos Direitos da Criança e do Adolescente (CONANDA), no item 9, onde diz que a criança hospitalizada tem o "Direito de desfrutar de alguma forma de recreação, programas de 
educação para a saúde, acompanhamento do curriculum escolar durante sua permanência hospitalar" (BRASIL, 1995, p.1). Nesse contexto, o Ministério da Educação criou em 2002, o documento que trata da Classe Hospitalar e Atendimento Domiciliar, determinando um perfil docente para exercer o cargo neste ambiente, em que:

O professor deverá ter a formação pedagógica preferencialmente em Educação Especial ou em cursos de Pedagogia ou licenciaturas, ter noções sobre as doenças e condições psicossociais vivenciadas pelos educandos e as características delas decorrentes, sejam do ponto de vista clínico, sejam do ponto de vista afetivo (BRASIL, 2002, p. 22).

Esse profissional deverá possuir conhecimentos específicos da realidade e condição das crianças e adolescentes internados, necessários para o desenvolvimento de sua função porque poderá enfrentar desafios e situações que exigirão conceitos clínicos sobre enfermidades, rotina e técnicas utilizadas no hospital, por isso a importância deste debate está incluído na formação inicial do pedagogo.

Alguns autores como Fonseca (1999) e Ceccim (1999), afirmam que o docente deve possuir a "destreza", ou seja, conhecer e compreender a realidade do educando e a partir desse ponto, iniciar sua intervenção, relacionando seus conhecimentos pedagógicos, centralizando-se no desenvolvimento e na aprendizagem da criança, respeitando a sua condição, o que denota uma prática desafiadora.

Este desafio é notório, pois a intervenção docente é o prelúdio do desenvolvimento e aprendizagem dos alunos, que contribui para a formação dos indivíduos, além de causar transformação nas relações e comportamentos dos membros da sociedade. Portanto, proporcionar um atendimento pedagógico no hospital não é transplantar a escola para o hospital, mas desenvolver modelos de intervenção pedagógica que levem em conta as características do ambiente hospitalar e da posição existencial da criança real (TAAM, 2004).

As atividades pedagógicas no hospital devem ser pensadas considerando o seu público alvo, ou seja, as crianças enfermas que 
frequentam a classe hospitalar e que em sua maioria diferem de idade, série e ano escolar. Tem-se assim, um desafio para esse espaço, em que compreende-se que o currículo adotado neste espaço deva ser flexibilizado, atendendo assim, todas as crianças e adolescentes permitindo que sejam incluídas no processo ensino-aprendizagem.

Deve-se levar em consideração no planejamento do pedagogo, os interesses e conhecimentos que as crianças possuem, sendo assim, a atuação deste profissional na classe hospitalar tem como foco não,

[...] apenas manter as crianças ocupadas. As crianças estão crescendo e se desenvolvendo estejam ou não no hospital. $\mathrm{O}$ professor está lá apenas para estimulá-las através do uso de seu conhecimento das necessidades curriculares de cada criança (WILLES, 1987, p. 23, apud SOUZA, 2011, p. 261).

As relações estabelecidas dentro do hospital entre o professor e as crianças/adolescentes, possibilitam compreender as dificuldades e limites delas, facilitando assim, a tomada de decisão que o docente terá que fazer, no tocante aos conteúdos trabalhados, ao percurso metodológico e aos materiais utilizados.

Além de estabelecer uma relação com a criança, deve também relacionarse com os profissionais que a assistem e com o seu acompanhante trocando informações e percepções que propiciem uma melhor adaptação a essa realidade que lhe foi posta, minimizando medos, traumas e estresses, permitindo assim, que a mesma expresse seus sentimentos e possa buscar seu bem-estar. Logo, a atuação do pedagogo dentro do ambiente hospitalar preza primeiramente pela aprendizagem e desenvolvimento da criança, levando em consideração suas limitações físicas e dificuldades que aparecer (FONSECA, 2008).

Desse modo, as classes hospitalares têm como foco a potencialização de capacidades e habilidades dos sujeitos hospitalizados, buscando sempre a valorização da sua escolaridade como sujeito de direito à educação. O professor dentro deste ambiente é um mediador, que através de suas estratégias permite que as crianças e adolescentes, jovens ou adultos possam se sentir bem nesse espaço e dispostas a participar das atividades e interagir 
com os outros, então a prática deve possibilitar que tenham vontade de participar da classe hospitalar e consigam aprender, respeitando sempre as condições e limites de cada um (FRANCO; SELAU, 2011).

Em se tratando da criança e/ou adolescente hospitalizados, lembra-se que estes se encontram em uma condição especial, porque estão enfermos e cuidando de sua saúde, passando por tratamentos, fazendo uso de medicamentos, exames, entre outros procedimentos, por isso podem ter dificuldade para se concentrarem nas aulas e no desenvolvimento das atividades. Tendo isso em vista, Souza (2011, p. 261) aponta que:

O papel do pedagogo/educador, [...], é oportunizar à criança situações e espaços diversificados, orientados para promover aprendizagens significativas que contribuam para garantir a continuidade do seu processo de desenvolvimento e aprendizagem e ao mesmo tempo criar formas de lidar com o tempo e as situações de forma mais prazerosa, ou menos sofredora.

O caráter destacado pela autora é o prazer em detrimento do sofrimento, tendo em vista que cotidianamente, a criança/adolescente por vezes se encontra suscetível a situações de vulnerabilidade, fragilidade, padecimento e insegurança. O trabalho desenvolvido pelo pedagogo no atendimento escolar hospitalar necessita então, se apresentar como uma prática educativa e estimuladora, proporcionando acesso a conhecimentos acumulados historicamente. Deve assim desprender-se da conotação referente à promoção de assistência ou cuidado, pois essa ação de ensinar transcende essas fronteiras (OLIVEIRA; LIMA, 2014) porque o objetivo é favorecer à criança, o acesso a educação no período em que está internada, facilitando sua adaptação na escola quando posteriormente retornar a suas atividades (FONSECA, 2008) e dar continuidade ao seu processo de escolarização.

Percebe-se a complexidade de um atendimento escolar no hospital, pois leva em conta todos os elementos já citados no texto, por isso a importância de se efetivar práticas neste contexto ainda na formação inicial para que, a exemplo do pedagogo, possa vivenciar situações divergentes do contexto educacional regular e avançar para novas frentes de trabalho. 


\section{Atendimento escolar hospitalar: concepções de alunas/professoras}

Como já anunciado a formação de professores precisa atentar para as demandas do processo de inclusão educacional em espaços não escolares. Este estudo traz o debate do atendimento escolar hospital no contexto da formação inicial do pedagogo, por isso se baseia numa perspectiva de abordagem qualitativa porque atenta para uma realidade e permite:

[...] a compreensão do cotidiano como possibilidades de vivências únicas, impregnadas de sentido, realçando a esfera do intersubjetivo, da interação, da comunicação e proclamando-o como espaço onde as mudanças podem ser pressentidas e anunciadas (GHEDIN; FRANCO, 2011, p.61).

Nesta compreensão, o contato com a realidade é fundamental e a análise recai sobre o projeto de extensão "Estudar, uma ação saudável", desenvolvido no Hospital Universitário da Universidade Federal do Maranhão, vinculado ao curso de Pedagogia desta universidade e classifica-se como um estudo de caso, uma vez que este segundo Yin (2010), se insere num foco de interesse e precisa ser um fenômeno contemporâneo e esteja ocorrendo numa situação de vida real.

Por se tratar de um fenômeno que esteja ocorrendo, os dados foram gerados pela técnica da Observação Participante e da Entrevista Semiestruturada, pois esta induz ao pesquisador que "[...] ser bom ouvinte significa ser capaz de assimilar grandes quantidades de novas informações imparcialmente" (YIN, 2010, p. 96). Como bom ouvinte, nesta técnica, não se pode perder de vista o foco do estudo e o tipo de informação que se busca.

Os sujeitos da pesquisas foram três alunas do Curso de Pedagogia, participantes do referido projeto de extensão, atuantes como bolsistas e voluntárias, que serão denominadas neste texto de B1, B2 e V1.

A ação docente no hospital é complexa até para um pedagogo que já tenha concluído sua graduação, quiçá para aqueles que estão processo de formação 
inicial. Os desafios desta ação precisam ser visualizados pelas alunas/professoras, para tanto foi preciso conhecer o que pensam sobre este tipo de atendimento, cujas respostas demonstraram como um "espaço novo de atuação" (B1), “o aprofundamento sobre o tema se deu nas reuniões de estudos do projeto" (B2) e a "experiência da ação serviu para a formação, pois o currículo do curso não proporciona nenhuma disciplina que atenda esta demanda" (V1).

As alunas/professoras têm ciência da necessidade de um debate sobre o tema na formação inicial, pois reconhecem que o campo de atuação do pedagogo está ampliado e o ato de ensinar no hospital possui peculiaridades diferentes do contexto da escolar regular, além do mais, deve-se problematizar a docência, uma vez que esta não é neutra, não se restringe apenas ao conteúdo, é intencionalizada na relação com um sujeito aluno, por isso é "[...] didático-pedagógica e, acima de tudo, compreensão da política educacional na qual tal prática se insere” (LIMA, 2001, p.143)

Assumir a tarefa de ensinar no hospital demanda responsabilidade com a formação e em se tratando de educação não escolar é preciso romper algumas barreiras, especialmente as amarras da educação como uma prática eminentemente escolar. Com isso, podem-se explorar outros cenários que vislumbrem a possibilidade da educação se constituir como um elo entre o sujeito e o mundo. Diante disso, destaca-se a importância da extensão universitária na formação inicial acadêmica dos pedagogos, pela possibilidade que essas experiências oferecem para a promoção e ampliação da atuação deste profissional (RABELO, 2014).

Sabe-se que o ambiente hospitalar possui características e rotina próprias e que o pedagogo deve adaptar a sua prática às mesmas. Visando a compreensão do desenvolvimento das atividades pedagógicas, perguntou-se sobre a rotina das ações desenvolvidas no projeto Estudar, uma ação saudável, as docentes assim descreveram:

Após o lanche das crianças começamos as atividades na brinquedoteca, chamamos as crianças em seus leitos para participarem das atividades, essas são voltadas para leitura e 
escrita, e sempre buscamos conciliar tais práticas com o que observamos no dia a dia das crianças internadas. (B1)

Começamos nossas atividades após o lanche, às 9h30. Mas antes passamos nos leitos para convidar as novas crianças, as que não conhecem a Brinquedoteca, a participar das atividades. E motivamos as que já conhecem a continuarem indo. Com relação às atividades desenvolvemos todas as atividades possíveis das diversas disciplinas. Língua Portuguesa, Matemática, Geografia, História, Arte, etc. (B2) Rodas de conversa com as crianças, e ouvi-las sempre que quiserem falar, pois é a partir daí, que vamos identificando possíveis problemas, e recebendo o retorno positivo e negativo de nossas ações. Explicações e aplicações de atividades, com temas variados e adaptadas para as diversas faixas etárias que recebemos, sempre levamos mais de uma atividade para que todos possam se sentir incluídos e participem. (V1)

B1 e B2 ressaltam que o atendimento escolar inicia-se depois do lanche, primeiramente tem-se o momento de motivação que acontece com as visitas aos leitos, estimulando-as a participarem das atividades, além de identificarem quem recebeu alta e quem continua internado. É crucial para o desenvolvimento da criança, que ela se interesse e se sinta segura em conhecer e participar do atendimento escolar hospitalar, para que aconteça a relação estabelecida entre a escola e o aluno, tolhidos pelo ato da hospitalização. Esta relação deve ser pautada em confiança e se transcorrer a partir de diálogos, ou seja, conhecer quem é aquele sujeito e compreender seus anseios e angústias.

Pela observação participante, percebeu-se que diariamente, as visitas médicas, os exames e outros procedimentos acontecem em sua maioria, no horário da manhã, por isso nesse período, é necessário que haja uma harmonia entre as atividades médicas e o atendimento escolar hospitalar. Após esses procedimentos, as crianças se alimentam e assim podem adentrar ao espaço pedagógico, que no hospital pesquisado, acontece na sala da Brinquedoteca Hospitalar. Para o docente atuante no ambiente hospitalar é importante "ter um bom conhecimento da rotina do hospital facilita tanto o trabalho da escola hospitalar como um todo quanto o planejamento do professor" (FONSECA, 2008, p. 45). 
Visando proporcionar, da melhor maneira, condições propícias para que haja aprendizagem significativa, o professor deve refletir sobre sua prática, assim como destaca B1, salientando que no decorrer das atividades, possa analisar o desenvolvimento de cada criança de forma crítica, observando a participação, o comportamento das crianças/adolescentes e também sua interferência como aluna/professora, em que de acordo com o que foi observado fará modificação em suas atividades propostas. Neste sentido, compreende-se que tal reflexão sobre as relações vivenciadas na sala servirão como base para o aprimoramento do trabalho pedagógico.

A partir da observação da prática de B1, B2 e V1, pode-se perceber que a mesma se divide em momentos conforme apontado por elas, em que há o convite nos leitos para participação das atividades. Após esse período as alunas/professoras esperam as crianças na sala, onde acontece a aula. O próximo momento é a roda de conversa que se caracteriza por "um espaço de partilha e confronto de ideias, onde a liberdade da fala e da expressão proporciona ao grupo como um todo, e a cada indivíduo em particular, o crescimento 'na compreensão dos seus próprios conflitos'" [...] (ANGELO, 2006, p. 5, grifo do autor).

Compreende-se que a troca de informações, experiências e sentimentos é crucial para o desenvolvimento de cada criança/adolescentes, que além de propiciar a oralidade (verbalizando aos demais o que sente e pensa), possibilita aos mesmos, permitir-se participar de uma das atividades pedagógicas, se percebendo como sujeito ativo nesse processo de aprendizagem (SANTOS; FARAGO, 2015).

Nesse atendimento há também o desenvolvimento de atividades das diversas áreas de conhecimento, como aponta B2, tendo como foco as duas habilidades descritas por B1, a leitura e escrita. De acordo com Rabelo (2014, p. 107), que desenvolveu uma pesquisa sobre o projeto:

O foco do projeto de extensão iniciou-se com a leitura e a escrita porque antes de iniciar as atividades no hospital foi feito um levantamento com as crianças através de uma ficha 
perfil [...] que constatou uma quantidade expressiva de crianças com dificuldades de leitura e escrita.

Buscando enfrentar as dificuldades vivenciadas pelas crianças participantes do Projeto "Estudar, uma ação saudável", foi pensado em uma prática que interviesse exatamente nessas competências, tendo como foco a superação desse obstáculo.

Deve-se ter em mente que a classe hospitalar enfoca a continuidade no processo de aprendizado iniciado na escola regular, que nos anos iniciais abrange a apropriação da língua materna, relacionando com disciplinas diversificadas, ou seja, promove o desenvolvimento do processo de escolarização através da interdisciplinaridade.

Ainda pela observação participante o foco na leitura e na escrita acontece a partir de atividades que envolvem diálogos e contações de histórias (potencializando a oralidade), produções artísticas (explorando técnicas diferenciadas, como mosaico, estilo grafite, origami, desenvolvendo a coordenação motora), entre outras que per mitem a criança apropriar-se dos conhecimentos de maneira lúdica. V1 aponta que existem na sala, crianças de diferentes idades e nível de desenvolvimento, logo, a prática proposta pela aluna/professora deve possibilitar a participação e interação de todos, por isso o uso de atividades diversificadas.

Com o intuito de compreender os desafios existentes no espaço hospitalar, foi perguntado sobre as dificuldades e limitações vivenciadas no cotidiano hospitalar, B1 destaca a necessidade de uma proposta que atenda as peculiaridades momentâneas da criança, promovida pela hospitalização, ou seja, "é preciso respeitar a patologia do paciente", contudo lidar com o diagnóstico da criança requer conhecimentos específicos e que o supera no diálogo com os profissionais da saúde, relata B2. Um grande desafio destacado por V1 é o tempo da aula, pois as atividades devem começar e terminar no mesmo dia, sem falar na separação com as crianças/adolescentes advindas da alta ou da perda, "já passei por duas perdas, uma me abalou muito, pois eu era próxima a criança, e só soube que ela veio a óbito, meses depois, isso é triste". 
Os desafios apontados pelas aluna/professoras denunciam uma prática diferenciada de ser professor, por conta do sujeito/aluno está em condições especiais e o espaço ser divergente da escola, contudo, vale lembrar que este sujeito tem direitos e o acompanhamento educacional no período de internação é um direito da criança, conforme reza a Resolução 41 (BRASIL, 1995), a reformulação da LBDEN(BRASIL, 2018)) e o documento do MEC, Classe Hospitalar e Atendimento Domiciliar (BRASIL, 2002), e tais dispositivos legais ainda não são alcançados em todos os hospitais, apesar de existirem atividades esporádicas desenvolvidas em Brinquedotecas Hospitalares sem cunho educacional, apenas terapêutico, o que minimiza o sofrimento reverberado pela hospitalização. Estas atividades são diferenciadas do projeto aqui investigado, que apesar de não ter ligação com as escolas de origem, desenvolve atividades escolares voltadas a minimizar as dificuldades de aprendizagem evidenciadas nas crianças/adolescentes hospitalizados.

Reafirma-se que as discussões sobre o atendimento escolar no hospitalar deve ser foco de debates na formação inicial do pedagogo, porque senão haverá vazios e lacunas na qual trará para ele limitações e dificuldades no enfrentamento de situações cotidianas, quando por ventura, este profissional se deparar nesta função, encontrando-se por vezes perdido e confuso, quando de sua atuação no hospital (FONSECA, 2008).

Outro grande desafio é em relação a perda das crianças, em especial o óbito, tal fato torna-se complexo na convivência, uma ve que:

O óbito das crianças e adolescente hospitalizados deixa não só o professor fragilizado, mas afeta também os demais alunos, pois além da perda de seus colegas, certamente terão medo que o mesmo venha a acontecer com eles. Para que os choques sejam amenizados, o profissional da classe hospitalar deve procurar trabalhar com e seus alunos, assuntos que abordem a realidade do óbito [...] (CARVALHO, 2011, p. 26).

Há assim, a necessidade de clareza e compreensão do contexto e situações que podem suceder no ambiente hospitalar, para assim, no exercício da prática pedagógica, enfatize-se conhecimentos que 
esclareçam e oportunizem o entendimento da realidade que as crianças e adolescentes internados estão sujeitas.

Além dos desafios impostos na realidade das alunas/professoras no espaço hospitalar, elas também apontaram avanços nesta experiência, como sendo "um novo espaço de atuação"(B1), envolver as crianças com as atividades escolares (B2), possibilitar a escuta coletiva (V1).

Percebe-se que se reconhecem com futuras profissionais que valorizam novas frentes de trabalho, na participação das crianças/adolescentes para promoção da aprendizagem, possibilitando interação social, ocasionado ruptura da individualidade ocasionada pelo leito e patologia, gerando aprendizagens duplas tanto na aluna/professora quanto no paciente/aluno e tal ato "é uma fonte de aprendizagem constante por meio da escuta às informações de vida da criança, com o seu conteúdo de representação da doença, do tratamento, da hospitalização e da equipe de saúde. [...]" (FONSECA, 2008, p. 37). Então, o atendimento escolar hospitalar é um rico espaço de aprendizagem e aperfeiçoamento da prática docente.

\section{Considerações finais}

A classe hospitalar garante a manutenção de uma ação presente na "antiga rotina" das crianças, a atividade escolar. O estabelecimento do vínculo com o conhecimento é uma estratégia para o enfrentamento de sua enfermidade, uma vez que há promoção do sentimento de bem-estar.

No que se refere à formação inicial para a atuação do docente, destacouse como limite, a ausência da oferta de conhecimentos sobre esse tema, visto que no currículo do Curso de Pedagogia da UFMA, não há uma disciplina específica para a temática, contudo, o projeto de extensão investigado possibilitou o contato com esse espaço, como campo de trabalho, a fim de contribuir para o processo formativo e estabelecer trocas de conhecimento e reflexões no tocante às vivências dentro do ambiente hospitalar. 
Ao analisar os avanços do atendimento escolar hospitalar, constatou-se que o Projeto de Extensão "Estudar, uma ação saudável” contribui para garantia do direito à educação, uma vez que oferece atividades pedagógicas intencionais e organizadas, criando a relação entre escola e hospital e na promoção da aprendizagem e desenvolvimento das crianças/adolescentes hospitalizados. O atendimento escolar hospitalar que acontece no referido projeto oportuniza o acompanhamento educacional-pedagógico construindo um ambiente propício para as mesmas apropriem-se significativamente de conhecimentos, favorecendo o seu desenvolvimento cognitivo e social.

Dessa forma, percebe-se que o atendimento escolar no hospital no Hospital Universitário da Universidade Federal do Maranhão alcança patamares além do exercício da docência que as alunas/professoras vivenciam, pois estabelece o vínculo entre educação e saúde, fator constante de debates nos dias atuais, bem como abarca ainda de forma incipiente, por não haver vínculo com a escola de origem do hospitalizado, o direito à educação.

\section{Referências}

ANGELO, Adilson de. A pedagogia de Paulo Freire nos quatro cantos da educação da infância. In: I CONGRESSO INTERNACIONAL DE PEDAGOGIA SOCIAL. 1. 2006. Anais. Faculdade de Educação, Universidade de São Paulo. Disponível em:

<http://www.proceedings.scielo.br/scielo.php?pid=msc0000000092006000100 001\&script=sci_arttext>. Acesso em: 10 fev. 2020.

BRASIL. Conselho Nacional dos Direitos da Criança e do Adolescente. Declaração dos Direitos da Criança e do Adolescente Hospitalizados. Resolução N. 41, de 13 de outubro de1995. Diário Oficial da União. Brasília: Imprensa Oficial, 199, de 17 de outubro de 1995, p.319-320, 1995.

BRASIL. Institui Diretrizes Curriculares para o Curso de Graduação em Pedagogia, licenciatura. Resolução CNE/CP $N^{o} 1$, de 15 de Maio de 2006. Brasília: Conselho Nacional de Educação, 2006.

BRASIL. MEC. Classe hospitalar e atendimento pedagógico domiciliar: estratégias e orientações. Brasília, 2002. 
BRASIL. Lei 13.716 de 24 de setembro de 2018. Altera a Lei 9.394 de 1996. Brasília. 2018. Disponível em: <http://www.planalto.gov.br/ccivil 03/Ato20152018/2018/Lei/L13716.htm>. Acesso em: 03 Fev. 2020.

CARVALHO, Karen Pina. Pedagogos hospitalares em Salvador: relatos e vivências. 2011. Monografia (Curso de Pedagogia). Universidade da Bahia, Salvador. Disponível em:

$<$ http://www.uneb.br/salvador/dedc/files/2011/05/Monografia-KarenPina.pdf>. Acesso em: 10 Dez. 2019.

CECCIM, Ricardo Burg. Classe hospitalar: encontros da educação e da saúde no ambiente hospitalar. Revista Pedagógica Pátio, n. 10, p. 41-44, ago/out. 1999.

FONSECA, Eneida Simões da. A situação brasileira do atendimento pedagógico-educacional hospitalar. Educação e Pesquisa, São Paulo, v. 25, n. 1, p. 117-129, jan./jun. 1999. Disponível em:

$<$ http://www.scielo.br/scielo.php?script=sci arttext\&pid=S1517-

97021999000100009>. Acesso em: 13 Jan. 2020.

FONSECA, Eneida Simões da. Atendimento escolar no ambiente hospitalar. 2.ed. São Paulo: Memnon, 2008.

FRANCO, Priscila de Fátima Pereira; SELAU, Bento. A atuação do pedagogo no ambiente hospitalar: algumas reflexões. Revista Liberato, Novo Hamburgo, v. 12, n. 18, p. 107-206, jul./dez. 2011. Disponível em:

<http://www.liberato.com.br/sites/default/files/arquivos/Revista_SIER/v.\%20 12\%2C\%20n.\%2018\%20\%282011\%29/7.a\%20atua\%E7\%E30\%20do\%20pedag ogo\%20no\%20ambiente\%20hospitalar.pdf>. Acesso em: 15 Jan.2020.

GHANEM, Elie; TRILLA, Jaume. Educação formal e não-formal. São Paulo: Summus, 2008.

GHEDIN, Evandro; FRANCO, Maria Amélia Santoro. Questões de método na construção da pesquisa em Educação. $2^{\mathrm{a}}$ ed. São Paulo: Cortez, 2011.

GLAT Rosana. Educação inclusiva: Cultura e Cotidiano Escolar. Rio de Janeiro: 7 letras, 2007.

GOMES, Marineide Pereira; SILVA, Yanatasha Fernandes Ferreira da; SILVA, André Gustavo Ferreira da. Educação não-formal: diálogos com a educação popular em Freire - o caso do grupo de leigos católicos igreja nova.2011.

Disponível em:

$<$ https://www.ufpe.br/ce/images/Graduacao_pedagogia/pdf/2012.1/educao\%20noformal\%20-\%20dilogos\%20com\%20a\%20educao\%20popular\%20em\%20fre.pdf.> Acesso em: 10 Jan. 2020. 
GOHN, Maria da Glória. Educação não-formal, participação da sociedade civil e estruturas colegiadas nas escolas. Ensaio: avaliação e políticas públicas em Educação, Rio de Janeiro, v.14, n.50, p. 27-38, jan./mar. 2006. Disponível em: < http://www.scielo.br/pdf/ensaio/v14n50/30405.pdf> Acesso em: 10 Jan. 2020.

LIMA, Maria do Socorro Lucena. A formação contínua do professor nos caminhos e descaminhos do desenvolvimento profissional. 2001. 169p. Tese (Doutorado em Educação). Universidade de São Paulo. São Paulo. 2001.

LIMA, Raíza S.; SILVA, Luciene; SANTOS, Luciana Lima dos. O trabalho do pedagogo em espaços não escolares: a formação do educador e o exercício da sua profissão. Anais do VI Fórum Internacional de Pedagogia. 2014. Santa Maria, RS: Editora Realize. Disponível em: <https://editorarealize.com.br/revistas/fiped/trabalhos/Modalidade 2datahor a $14 \quad 06 \quad 2014 \quad 13 \quad 56 \quad 11$ idinscrito $1666 \quad 381 \mathrm{f} 714 \mathrm{e} 0 \mathrm{f} 2 \mathrm{a} 673 \mathrm{fb} 33 \mathrm{~b} 5772 \mathrm{~b} 90384$ d1.pdf>. Acesso em: 10 fev. 2016.

MATOS, Elizete Lúcia Moreira; MUGGIATI, Margarida M. Teixeira de Freitas. Pedagogia Hospitalar: a humanização integrando educação e saúde. Petrópolis, RJ: Vozes, 2007.

MOURA, Eliana Perez Gonçalves de; ZUCCHETTI, Dinora Tereza. Educação além da Escola: acolhida a outros saberes. Cadernos de Pesquisa, v.40, n.140, p. 629-648, maio/ago. 2010. Disponível em:

<http://www.scielo.br/pdf/cp/v40n140/a1640140.pdf.> Acesso em: 12 Jan. 2020.

NASCIMENTO, Aretha Soares. et al. A atuação do pedagogo em espaços não escolares: desafios e possibilidades. Pedagogia em Ação, v. 2, n. 1, p. 1-103, fev./jun. 2010. Disponível em:

<http://periodicos.pucminas.br/index.php/pedagogiacao/article/view/4481>.

Acesso em: 15 Jan. 2020.

OLIVEIRA, Maria Cecília Marins de, e LIMA, Tatiane Delurdes de. Pedagogia Hospitalar: a Prática Pedagógica no Espaço Hospitalar. Revista Kur'yt'yba. 2014. Disponível em:

http://revista.cmc.ensino.eb.br/index.php/revista/article/view/41. Acesso em: 10 Jan. 2020.

RABELO, Francy Sousa. Educação não escolar e saberes docentes na formação do pedagogo: análise de uma experiência no espaço hospitalar. 2014. 184p. Dissertação (Mestrado em Educação). Universidade Estadual do Ceará. Fortaleza, 2014. 
SANTOS, Maria Gabriela da Silva; FARAGO, Alessandra Corrêa. $O$ desenvolvimento da oralidade das crianças na Educação Infantil. Cadernos de Educação: Ensino e Sociedade. Bebedouro: SP, 2015.

SOUZA, Amaralina Hiranda de. Formação do pedagogo para trabalhar no contexto hospitalar. Linhas Críticas. v. 17. n. 33. Brasília, DF. 2011. Disponível em: <https://www.redalyc.org/pdf/1935/193521546005.pdf $>$. Acesso em: 13 Jan.2020.

TAAM, Regina. Pelas trilhas da emoção: a educação no espaço da saúde. Maringá: Eduem, 2004.

YIN, Roberth K. Estudo de caso: planejamento e métodos. 4. ed. Porto Alegre: Bookman, 2010. 